\title{
0 desenvolvimento da Psicologia Social na América Latina
}

\author{
DięoViniausda Silva - UniversidadeSãoFranisco, Itatiba, SãoPaulo, Brasil
}

O rtega, J. J. V . (2012). Pespetiva psicosoial aproximadiones histónicasyẹistemlóġaseintervenión México: Itaca.

No livro "Pespeetiva psicosocial aproximadiones histónicas y epistemdógicas e intervenaón", coordenado por José Joel Vázquez Ortega, psicólogo social e conselheiro executivo da Unión Latinoamericana de Entidades en Psicoloǵa (ULAPSI), apresenta-se a contribuição de diferentes autores da psicologia social referente à sua conceituação teórica e prática profissional. Atualmente, O rtega preside a Ascaiación de Egresados de Psicooǵa Scial e coordena o Programa Intervenión Psicosocial y Comuitario en Deeehos Humanos Além disso, realiza pesquisas sobre psicologia social e leciona em diferentes instituições de ensino no México.

O prólogo é escrito pelo próprio coordenador do livro, José O rtega, no qual se destaca a psicologia social como um processo de construção, fazendo-se ainda necessário organizar a estrutura dessa área com elementos estudados por diferentes autores. 0 livro está organizado em três partes: na primeira se apresentam aspectos históricos sobre a constituição da psicologia social, na segunda se apresentam questões de caráter epistemológico e na terceira parte se descrevem experiências práticas de psicólogos sociais de países latino-americanos. Ortega destaca a importância de se construir um referencial teórico da América Latina a partir de questões associadas com essa realidade sociocultural, na expectativa de consolidar uma teoria específica latino-americana, desfazendo-se assim a dependência de alguns estudiosos que fundamentam suas pesquisas nos modelos propostos por outras realidades sociais, principalmente, de países americanos e europeus.

No primeiro capítulo, denominado "Apotaciones de desamdlo de la psicolóa soial en y desde latianaméica", José Joel Vázquez Ortega descreve um conjunto de contribuições observadas no desenvolvimento da psicologia social na América Latina. Inicialmente, as práticas da psicologia social na América Latina estavam associadas às teorias estruturadas em outras regiões, especialmente nos Estados Unidos e Europa. Nos países latino-americanos, a prion, a contribuição mais importante foi em relação à psicologia social comunitária, como prática alternativa, esperançosa e crítica. Esse trabalho visa identificar que a violência política e a guerra psicológica estão entre os principais instrumentos de domínio e controle de grupo de seres humanos. Assim, o trabalho nessa região implica ser sensível ao sofrimento, característica desses países no qual a subjetividade deve ser considerada nas intervenções.

O capítulo "Pensamiento arganizacional: una reisión históica desdela psicdoǵa soial”, escrito por Xavier Pons Díez e José Luis Ramos Miralles, se configura como uma revisão histórica da psicologia social inserida na área organizacional, ou seja, busca-se compreender 0 pensamento organizacional sob a influência da psicologia social. Aspectos históricos do campo organizacional (e.g. Revolução Industrial e tecnológica) modificaram 0 trabalho e a produção, sendo importante estudar essas modificações, porém considera-se importante estudar cientificamente também o trabalhador. Este deve ser investigado, assim como os grupos sociais que emergem do ambiente organizacional.

No terceiro capítulo, "En lengrajey sus feetos en las institudions", Juan Manuel Herrera Caballero e N. Georgina Martell Martínez discutem sobre os novos significados atribuídos pelos trabalhadores dentro dos ambientes organizacionais. Toda organização, por meio de regras e valores, contribue para o desenvolvimento de significados dos trabalhadores, no sentido de compreender e vivenciar essa dinâmica organizacional. As interações no ambiente de trabalho também influenciam na manutenção do aspecto simbólico do trabalho, no qual se deve considerar 0 aspecto psicológico, como as estruturas de personalidade.

Em "El dibujo como una medida deidentidad en niños ind'genas migantes", José Ángel Vera Noriega, María Enriqueta Lunez Pérez e Reyna Guadalupe Castillo Vega buscaram identificar as diferenças em relação à identidade social de dois grupos de filhos de trabalhadores agrícolas: um grupo formado por crianças migrantes do noroeste do México e outro grupo formado por crianças procedentes da região da Montaña Baja do estado de Guerrero. A identidade social foi avaliada por meio de desenhos da família, casa, árvore e pessoa. Encontraram-se diferenças significativas nos dois grupos, sendo que aqueles que falam a língua local (de Guerrero) apresentaram os desenhos menos expressivos de todos. Assim, os autores discutem os resultados dessa pesquisa por meio da teoria de identidade social e suas implicações no desenvolvimento psicológico e social.

No capítulo denominado "Reess soiales y reinserión soial. El caso de primoddinauntes reién liberados", Victor Gerardo Cárdenas González e Erika Berenice Cortés 
Velázquez entrevistaram um grupo de pessoas que recuperaram a liberdade depois de um período de internamento em prisões mexicanas. O s autores partem da premissa que esses indivíduos são vulneráveis a reincidência de delitos, dependência de drogas e outras formas de exclusão social. Os autores descrevem seis casos estudados nessa pesquisa nos quais percebe-se que existe um distanciamento das redes familiares, assim como a rede interna (Fundación Familia Alternativa A. C.) não satisfaz as necessidades subjetivas dessas pessoas.

No sexto capítulo, "Desafíos y fortalezas en familias latinoameicanas", María Rosario Espinosa Salcido descreve os desafios enfrentados pelas famílias latinoamericanas na atualidade, considerando a família como um campo privilegiado de investigação e interação social. Entre os principais problemas sociais descritos no trabalho de Salcido, destacam-se os problemas escolares (e.g. baixo desempenho escolar, dificuldades para cumprir as tarefas), violência familiar, problemas na comunicação, problemas de condutas dos jovens, depressão e conflitos conjugais. D estaca-se também dessa análise a capacidade de adaptação das famílias latino-americanas, a resiliência, comum nessas situações de risco, que permite enfrentar novos desafios.

No sétimo capítulo, "El trabajo dela picoloǵa en d ámbito de los deechos humanos. Una experienda dilena", Valeria Moscoso Urzúa descreve uma experiência de trabalho psicológico em direitos humanos realizado no
Chile. O bserva-se que este é um país onde houve um retrocesso nas questões de direitos humanos (e.g. Golpe de Estado das forças armadas de 1973, que durou 17 anos). Nesse período, muitas das manifestações sintomáticas apresentadas pelas pessoas que procuravam o profissional de saúde mental foram causadas pela violência e repressão social.

Por fim, no último capítulo, "Luma darea y campesina en Guatemala. Aproximaciones psicosciales y rearcimiento histónø", José Joel Vázquez Ortega e Juan Cristóbal Aldana Alfaro realizam uma investigação sobre a forma como a degradação de símbolos e as lutas esquecidas são alguns dos processos gerados pela cultura hegemônica e pelos grupos de poder. Analisamse nesse capítulo os acontecimentos mais significativos do movimento operário e camponês ocorrido na Guatemala durante a luta anti-imperialista no século XX.

De maneira geral, esse livro tem o propósito de registrar algumas contribuições de pesquisadores sobre temas, problemas, intervenções e reflexões da psicologia social para moldá-la em uma psicologia social humanizante e libertadora. Nesse sentido, o livro é destinado aos pesquisadores e profissionais das áreas sociais e humanas, pois as experiências nele apresentadas permitem uma reflexão acerca das intervenções da psicologia no cenário social, principalmente para os profissionais da América Latina.

Sobre 0 autor:

Diego Vinicius da Silva é psicólogo, doutorando em Avaliação Psicológica pela Universidade São Francisco, professor da Faculdade de Ciências Sociais Aplicadas de Extrema.

Contato com o autor:

Faculdade de Ciências Sociais Aplicadas de Extrema. Estrada Municipal Pedro Rosa da Silva S/ N - Vila Rica CEP 37.640-000. Extrema - MG.

E-mail: vinicius.diego@ymail.com 